\title{
Discussion On The Optimization of Circumferential Distance Of The System Bolt In A Highway Tunnel
}

\author{
Wang Kun ${ }^{1,2}$, Yu Shun ${ }^{1,2}$, Pan Yong ${ }^{1,2 *}$, and Lushi Wang ${ }^{1,2}$ \\ ${ }^{1}$ China Merchants Chongqing Communications Technology Research \& Design Institute Co., Ltd., Chongqing, 400067, P.R.China \\ ${ }^{2}$ National Engineering Laboratory For Highway Tunnel Construction Technology, Chongqing 400067 P.R.China
}

\begin{abstract}
The setting of circumferential distance of system anchor rod in highway tunnel is related to the safety of tunnel structure, and also affects the project cost. The "code for design of highway tunnels" issued in 2018 also adjusted the circumferential spacing arrangement of the system bolts of the tunnel. Based on a highway tunnel project, the circumferential spacing of system bolts in deep buried section of grade $\mathrm{V}$ surrounding rock is adjusted from $0.8 \mathrm{~m}$ to $1.2 \mathrm{~m}$, and the numerical simulation and comparative analysis before and after the optimization of bolt spacing are carried out. The field monitoring and measurement data show that the surrounding rock deformation after adjustment has little effect, and the cavern is stable as a whole, which can guide the optimization implementation of subsequent sections.
\end{abstract}

\section{Introduction}

System anchor bolts are an important part of the primary support structure of a tunnel. Traditional theory holds that system anchor bolts has the functions of suspension, span reduction, reinforcement and composite beam, etc. [1], and recommended range for system anchor bolt spacing setting is also given in relevant specifications ${ }^{[2]}$. In recent years, with the construction of a large number of tunnel projects, based on the understanding of the efficiency of system anchor bolts and the saving of project investment, a lot of researches have been carried out on the spacing of system anchor bolts in the industry.

Through the simulation and comparison of bolt parameters (bolt length, bolt spacing and bolt diameter), $\mathrm{Xu}$ Ligong ${ }^{[3]}$ et al. concluded that bolt length has the most obvious effect on improving the stability of surrounding rock, followed by bolt spacing and bolt diameter. Li Dejun ${ }^{[4]}$ et al. believed that increasing bolt length and reducing bolt spacing within a certain range can effectively improve the stress of anchor bolts, but it has no obvious influence on the deformation of tunnel surrounding rock and the overall stress of primary support. Wang Zhiwei ${ }^{[5]}$ et al. used indoor model test and numerical simulation to study the optimality of bolt spacing in three-lane large-section tunnel with class-IV surrounding rock, and the results showed that the optimum interval of bolt spacing was $1.0 \times 1.0 \mathrm{~m} \sim 1.0 \times$ $0.75 \mathrm{~m}$. Yin Haibo ${ }^{[6]}$ et al., through numerical simulation, reduced the bolt spacing, and found that there was no obvious concentration phenomenon of vertical stress on the two sides of the laneway, but when the bolt length was increased, the vertical stress tended to concentrate on the two sides of the laneway.
Meng Yafeng ${ }^{[7]}$ et al. found through monitoring data that the surrounding rock pressure, steel arch stress and clearance convergence with or without system anchor bolt support were basically the same, and the vault settlement with system anchor bolt support was reduced by $6.5 \%$ compared with that without system anchor bolts; tests have shown that the effect of system anchor bolts in large-section shallow-buried sandy clay tunnels is not obvious, and the system anchor bolts at arch can be cancelled. Shi Zhengbao, et al. conducted a comparative test of anchor bolt setting in Lijiazhai Tunnel, erected the steel arch in the class-IV soft surrounding rock section and cancelled the system anchor bolts. Shen Zhijun ${ }^{[8]}$ et al. demonstrated through tests that the stability requirements of tunnels can be satisfied without system anchor bolts, so the system anchor bolts were cancelled in the class-IV and class-V surrounding rock sections of the loess tunnel of Inner Mongolia-Jiangxi Railway. Chen Jianxun, et al. ${ }^{[9]}$ conducted a comparative test on several loess tunnels with and without system anchor bolts, and believed that the application of system anchor bolts delayed the best time of primary support, increased the deformation of surrounding rock, and the effect of system anchor bolts was not obvious; on the contrary, after canceling the system anchor bolts, the deformation and stress of the primary support structure of the tunnels are in good working condition, and system anchor bolts cancellation can significantly improve the quality and efficiency and reduce the cost.

The above studies show that there are still differences in the understanding of the effect of the system anchor bolts of tunnels. Under the current background of various engineering construction modes, for the purposes of balanced consideration of both the safety of tunnel structure and saving investment as much as possible, the spacing setting of system anchor bolts still has research

*Corresponding author: panyong15@126.com 
value for specific engineering projects. Based on a highway tunnel project in Yunnan Province, this paper optimizes and adjusts the spacing setting of the system anchor bolts of the tunnel system by numerical simulation and comparative analysis of field monitoring data.

\section{Project Overview}

\subsection{Original design}

The two-lane highway tunnel in Yunnan Province has a total length of about $2 \mathrm{~km}$, which passes through shale and slate strata, mainly class-V surrounding rock. Composite lining structure is adopted for the tunnel. In the original design, C25 shotcrete with a thickness of $25 \mathrm{~cm}$ is used for the primary support of the lining tunnel in the deep-buried section of class- $\mathrm{V}$ surrounding rock tunnel, C30 reinforced concrete with a thickness of $50 \mathrm{~cm}$ is used for the secondary lining, and $\varphi 25$ hollow grouting bolts with a length of $3.5 \mathrm{~m}$ are used as the system anchor bolts, which are arranged in a quincunx shape (as shown in Figure 1), and the circumferential spacing of the bolts is $0.8 \mathrm{~m}$; the longitudinal spacing takes $0.75 \mathrm{~m}$, which is consistent with the arch spacing.

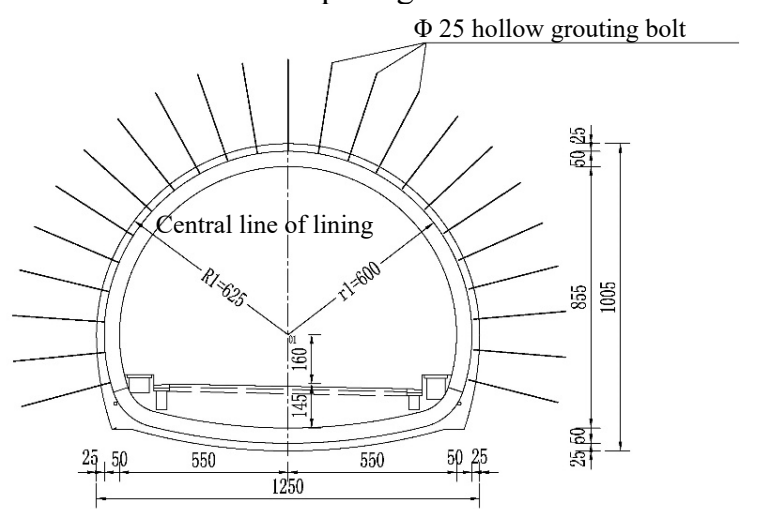

Figure 1. Section of Class-V Surrounding Rock Lining

\subsection{Bolt optimization and adjustment}

The construction of the deep buried section of class-V surrounding rock was started after the tunnel portal and its shallow buried section were completed. From the perspective of the surrounding rock monitoring and the stress condition of the supports in the previously completed sections, the primary supporting structure was basically stable. In the follow-up deep-buried class-V surrounding rock section, the field personnel proposed to optimize and adjust the spacing of system anchor bolts.
The adjustment scheme was as follows: the longitudinal spacing of anchor bolts remained unchanged, still taking $0.75 \mathrm{~m}$, and the circumferential spacing was adjusted from $0.8 \mathrm{~m}$ to $1.2 \mathrm{~m}$.

\section{Numerical Simulation on Optimization of Circumferential Spacing of System Anchor Bolts}

In order to analyze the changes of bolt axial force, surrounding rock displacement and the plastic zone before and after the spacing adjustment of the system anchor bolts, two kinds of calculation models were established by using finite element software according to the system anchor bolts circumferential spacing of $0.8 \mathrm{~m}$ and $1.2 \mathrm{~m}$ respectively.

\subsection{Calculation models}

In order to facilitate visual analysis, the models were simplified as a 2D plane strain problem. Four-node plane solid elements were used to simulate the surrounding rock mass, the primary support and the secondary lining structure of the tunnel, and two-node 2D beam elements were used to simulate tunnel bolts. To reduce the influence of boundary effect, the horizontal boundary on both sides of surrounding rock was taken as three times the width of tunnel, and the lower boundary was taken as three times the height of tunnel.

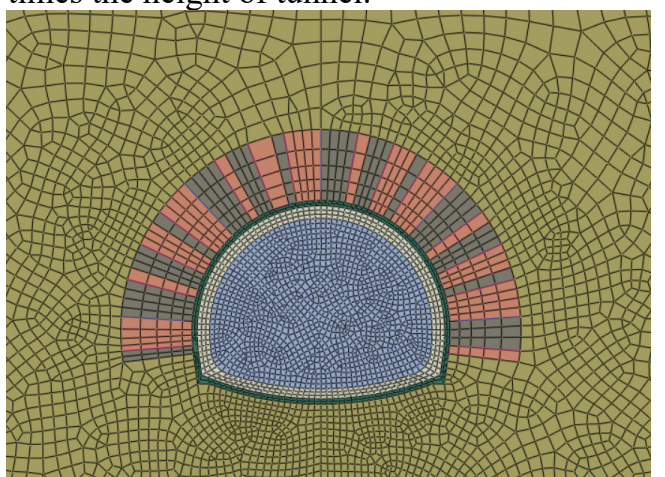

Figure 2. Stratum-Structure Finite Element Model

The material properties of the surrounding rock were considered as homogeneous elastoplasticity, the D-P yield criterion was used for calculation, and the material properties of supporting structure are considered as linear elasticity. See the following table (Table 1) for the values of material parameters of calculation models such as surrounding rock, shotcrete and anchor bolts.

Table 1. Parameters of Materials for Calculation Model.

\begin{tabular}{llllll}
\hline Item & $\begin{array}{l}\text { Density } \\
\rho /\left(\mathrm{kg} / \mathrm{m}^{3}\right)\end{array}$ & $\begin{array}{l}\text { Elasticity } \\
\text { modulus } \\
\text { E/ GPa }\end{array}$ & $\begin{array}{l}\text { Poisson } \\
\text { ratio } \\
v\end{array}$ & $\begin{array}{l}\text { Angle } \\
\text { internal friction } \\
\varphi(\circ)\end{array}$ & $\begin{array}{l}\text { Cohesion } \\
c(\mathrm{MPa})\end{array}$ \\
\hline Class-V surrounding rock & 2000 & 1.2 & 0.37 & 25 & 0.12 \\
$\Phi$ 25 hollowgrouting bolt & 7850 & 210 & 0.3 & - & - \\
C25 shotcrete & 2450 & 26 & 0.2 & - & - \\
\hline
\end{tabular}




\subsection{Bolt axial force}

After calculation, the axial force and tensile stress distributions before and after the adjustment of the circumferential spacing of the system anchor bolts were extracted (see Figure 3 and Figure 4). In terms of axial force, when the circumferential spacing of system anchor bolts was $0.8 \mathrm{~m}$, the maximum bolt axial force was 37.15 $\mathrm{kN}$; when the spacing was adjusted to $1.2 \mathrm{~m}$, the maximum bolt axial force was $43.95 \mathrm{kN}$, which was located in the vault area. The maximum bolt axial force was increased by about $18.3 \%$. In addition, the maximum tensile stress of anchor bolts was $75.68 \mathrm{MPa}$ when the circumferential spacing of system anchor bolts was $0.8 \mathrm{~m}$, and the maximum tensile stress was $89.53 \mathrm{MPa}$ when the spacing was adjusted to $1.2 \mathrm{~m}$, and the maximum tensile stress was increased by about $15.5 \%$.

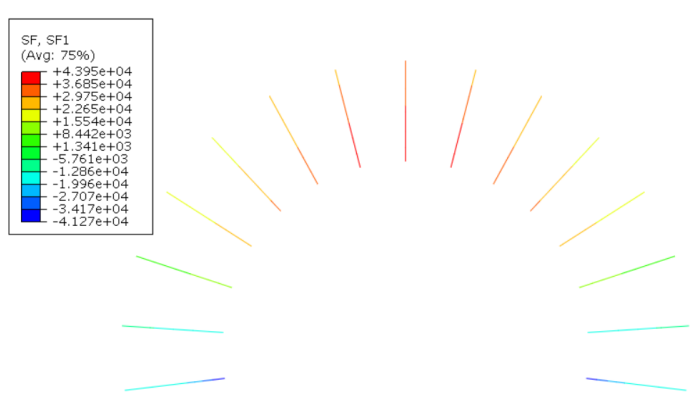

(a)Circumferential spacing of $\mathbf{0 . 8 m}$

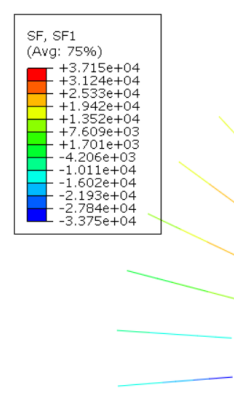

(b)Circumferential spacing of $1.2 \mathrm{~m}$

Figure 3. Distribution of Axial Force of Anchor Bolts

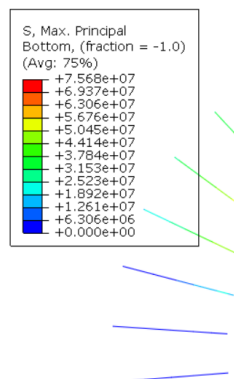

(a)Circumferential spacing of $\mathbf{0 . 8 m}$

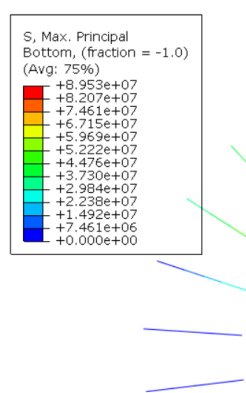

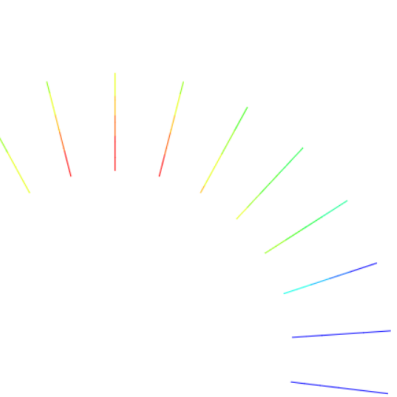

(b)Circumferential spacing of $1.2 \mathrm{~m}$

Figure 4. Distribution of Tensile Stress of Anchor Bolts

\subsection{Deformation of surrounding rock}

Figure 5 and Figure 6 are nephograms of displacement deformation of tunnels in vertical and horizontal directions, respectively. In terms of the vertical deformation, the maximum vertical displacement of the surrounding rock was $10.46 \mathrm{~mm}$ (uplift at the bottom of the invert) when the circumferential spacing of system anchor bolts was $0.8 \mathrm{~m}$; while the maximum settlement of vault was $6.43 \mathrm{~mm}$. In contrast, when the bolt spacing was adjusted to $1.2 \mathrm{~m}$, the maximum vertical displacement was $10.59 \mathrm{~mm}$ (located at the bottom of the invert), and the maximum settlement of the vault was $7.52 \mathrm{~mm}$. In addition, the maximum horizontal displacement before and after anchor adjustment was $2.79 \mathrm{~mm}$ and $3.07 \mathrm{~mm}$ respectively, and the horizontal displacement after adjustment was increased by $10.04 \%$, which was located in the arch foot area. 


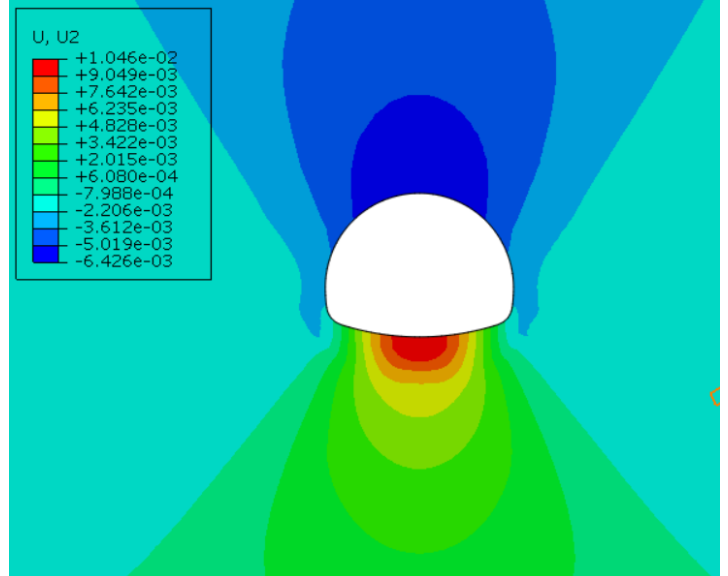

(a)Circumferential spacing of $0.8 \mathrm{~m}$

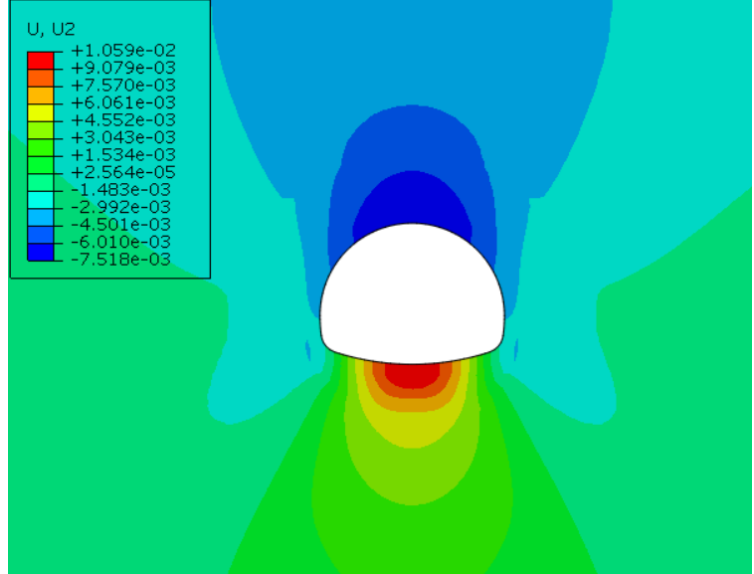

(b)Circumferential spacing of $1.2 \mathrm{~m}$

Figure 5. Nephogram of Tunnel Vertical Displacement

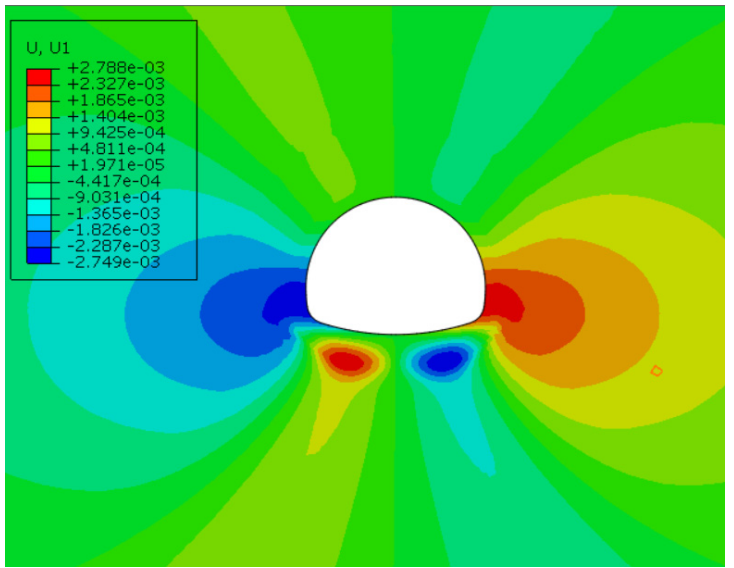

(a)Circumferential spacing of $\mathbf{0 . 8 m}$

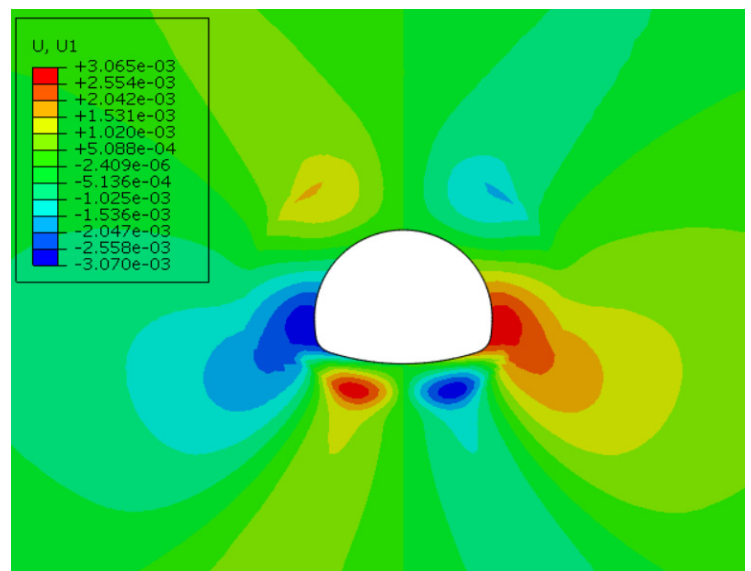

(b)Circumferential spacing of $1.2 \mathrm{~m}$

Figure 6. Nephogram of Tunnel Horizontal Displacement

symmetrically distributed. The change of bolt spacing had little effect on the maximum plastic deformation, and the maximum values before and after adjustment were

\subsection{Plastic zone of surrounding rock}

Figure 7 is the nephogram of plastic zone distribution of surrounding rock before and after adjustment of circumferential spacing of system anchor bolts. It can be seen that the maximum plastic deformation area of the surrounding rock under the two working conditions appeared at the bottom of the tunnel, which was

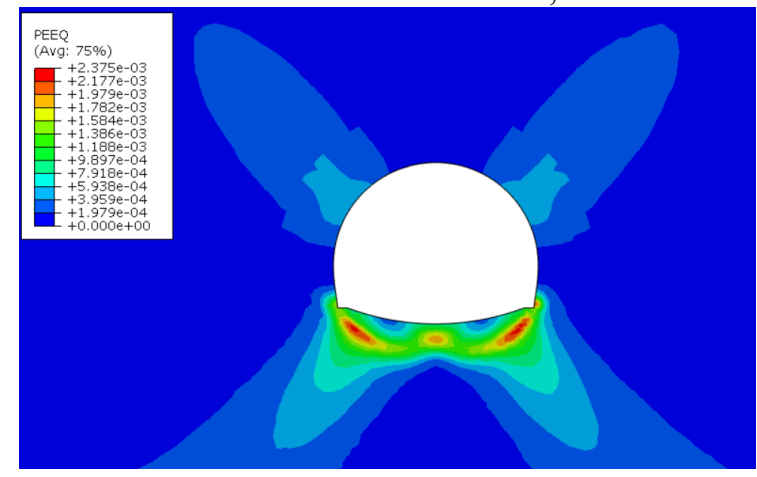

(a)Circumferential spacing of $\mathbf{0 . 8 m}$ $2.37 \times 10^{-3}$ and $2.38 \times 10^{-3}$, respectively. At the same time, it can be seen that the plastic range of local surrounding rock of vault increased with the increase of bolt spacing at the top of tunnel.

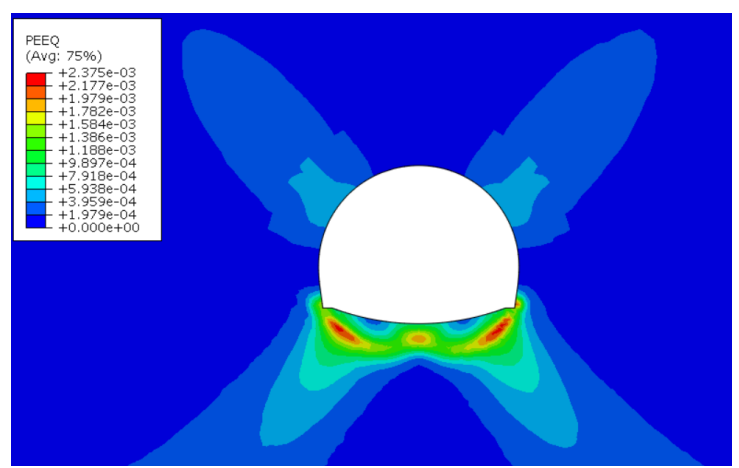

(b)Circumferential spacing of $1.2 \mathrm{~m}$

Figure 7. Distribution Nephogram of Plastic Zone of Surrounding Rock

The above studies show that there are still differences in the understanding of the effect of the system anchor bolts of tunnels. Under the current background of various engineering construction modes, for the purposes of balanced consideration of both the safety of tunnel structure and saving investment as much as possible, the 
spacing setting of system anchor bolts still has research value for specific engineering projects. Based on a highway tunnel project in Yunnan Province, this paper optimizes and adjusts the spacing setting of the system anchor bolts of the tunnel system by numerical simulation and comparative analysis of field monitoring data.

1. After the adjustment of the circumferential spacing of the system anchor bolts, the bolt axial force increases by about $15 \sim 20 \%$, but it is within the bearing capacity of the anchor bolts.

2. The adjustment of the circumferential spacing of system anchor bolts from $0.8 \mathrm{~m}$ to $1.2 \mathrm{~m}$ has little influence on the change of tunnel displacement and the overall deformation of surrounding rock.

3. The maximum plastic deformation areas of surrounding rock before and after bolt adjustment are both at the bottom of the tunnel, and the adjustment of bolt spacing has little influence on the plastic area of surrounding rock at the top of the tunnel.

\section{Comparative Analysis of Monitoring Measurement Data}

In the deep-buried test section of class- $\mathrm{V}$ surrounding rock, three groups of monitoring sections were set up respectively according to two working conditions of $0.8 \mathrm{~m}$ and $1.2 \mathrm{~m}$ circumferential spacing of system anchor bolts: $\mathrm{K} 6+510, \mathrm{~K} 6+525, \mathrm{~K} 6+550$ and $\mathrm{K} 6+570, \mathrm{~K} 6+585$, K6+600. The monitoring contents mainly included surrounding rock deformation, bolt axial force and surrounding rock-primary support contact pressure (hereinafter referred to as surrounding rock pressure). This paper selects a group of typical monitoring results for comparative analysis.

\subsection{Vault settlement monitoring}

The monitoring points for vault settlement were set at the vault, left spandrel and right spandrel of the same monitoring section. In the deep-buried class-V surrounding rock sections of the tunnel, the vault settlement data of $\mathrm{K} 6+520$ and $\mathrm{K} 6+585$ sections were selected for comparative analysis (see Figure 8).

The circumferential spacing of system anchor bolts at $\mathrm{K} 6+520$ section was $0.8 \mathrm{~m}$, the accumulative settlement of the vault, left and right spandrels were $39.4 \mathrm{~mm}, 27.02 \mathrm{~mm}$ and $31.49 \mathrm{~mm}$ respectively. The circumferential spacing of system anchor bolts at $\mathrm{K} 6+585$ section was $1.2 \mathrm{~m}$, the accumulative settlement of the vault, left and right spandrels were $43.15 \mathrm{~mm}, 31.52 \mathrm{mmmm}$ and $24.32 \mathrm{~mm}$ respectively.

From a general view, the settlement values at the vault of $\mathrm{K} 6+520$ and $\mathrm{K} 6+585$ sections were higher than those at the spandrels, and the accumulative settlement value of the vault of the former section was $3.75 \mathrm{~mm}$ smaller than that of the latter section, accounting for about $8.7 \%$. The deformation rates of surrounding rock at the two sections were both large in the early stage, but decreased in the later stage, and basically tended to be stable at the end of monitoring.

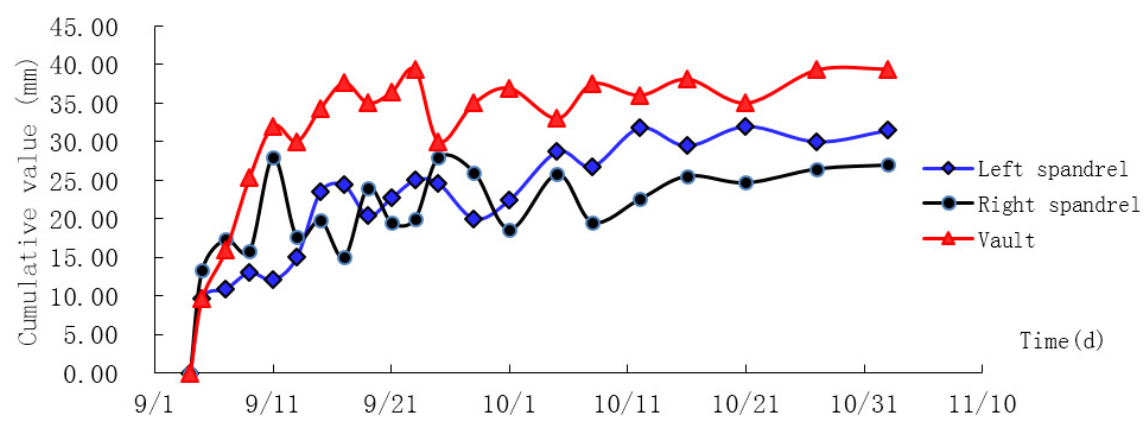

(a) Section K6+520 (bolt spacing 0.8m)

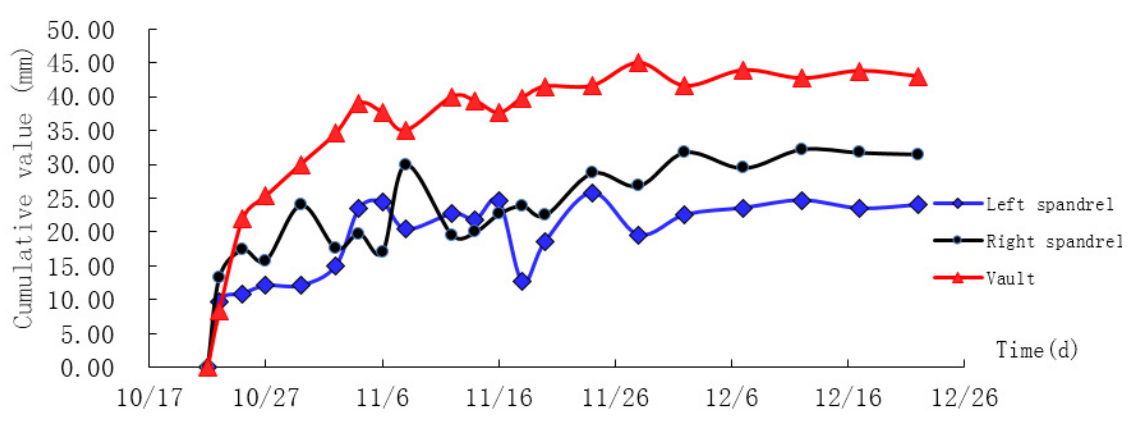

(b) Section K6+585 (bolt spacing 1.2m)

Figure 8. Vault Settlement Duration Curve 


\subsection{Monitoring of bolt axial force}

A four-node XJG-3 vibrating wire anchor dynamometer was used to monitor the bolt axial force, which was mainly arranged at the vault, spandrel and hance. The

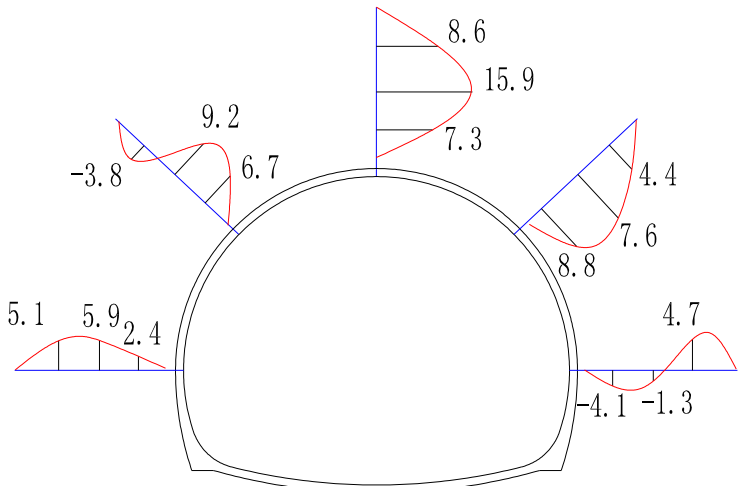

(a) Section K6+520 (bolt spacing $0.8 \mathrm{~m}$ )

monitoring data of bolt axial force at $\mathrm{K} 6+520$ and $\mathrm{K} 6+585$ sections were selected for comparative analysis (see Figure 9). In the figure, tension is positive and compression is negative.

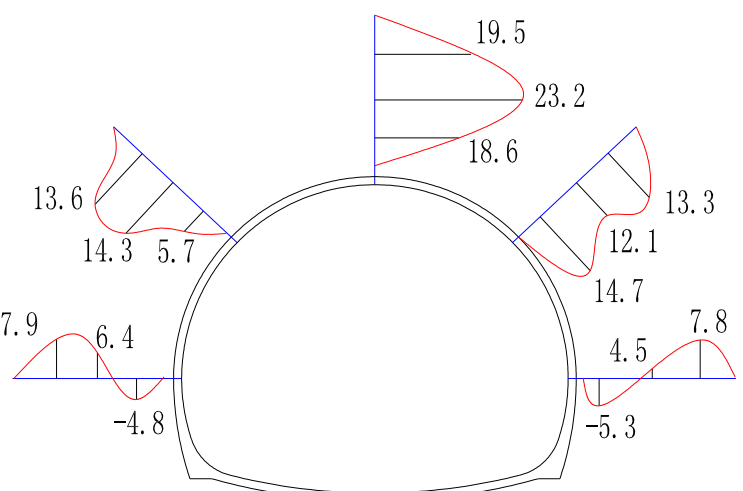

(b) Section K6+585 (bolt spacing 1.2m)

Figure 9. Envelope Diagram of Bolt Axial Force Distribution (unit: kN)

In general, in the two monitoring sections, the value of anchor axial force at the vault was the largest, while that at the hance was smaller. The maximum bolt axial force at $\mathrm{K} 6+520$ vault was $15.9 \mathrm{KN}$; and after adjusting the bolt spacing, the maximum bolt axial force at $\mathrm{K} 6+585$ vault was $23.2 \mathrm{KN}$, and the maximum bolt axial force was increased by $7.3 \mathrm{KN}$, with an increase amplitude of $31.4 \%$.

\subsection{Surrounding rock-primary support contact pressure}

The monitoring points were set at the vault, spandrel and arch foot of the same monitoring section. The

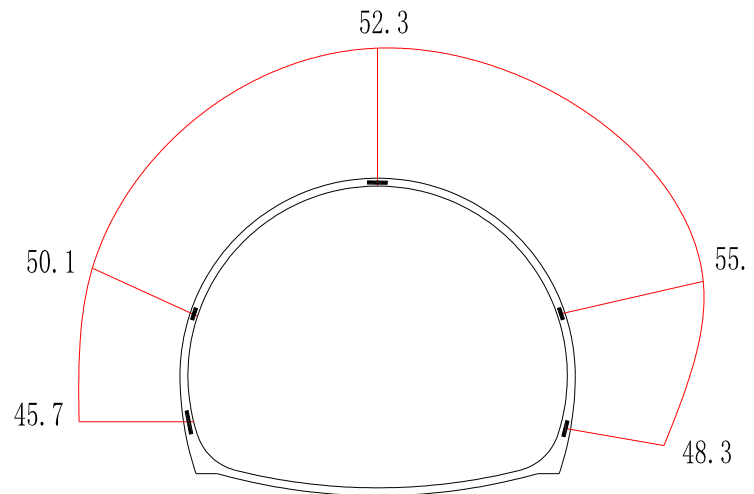

(a) Section K6+510 (bolt spacing 0.8m)

65.7 surrounding rock pressure monitoring data of $\mathrm{K} 6+510$ and $\mathrm{K} 6+570$ sections were selected for comparative analysis (see Figure 10). XYJ-6 double-membrane pressure cell was used for monitoring the surrounding rock pressure. In the monitoring process, the change rule of surrounding rock pressure was complicated. The maximum surrounding rock pressure of K6+510 was $55.7 \mathrm{KPa}$, and the minimum pressure was $45.7 \mathrm{KPa}$; after adjusting the spacing of system anchor bolts, the maximum surrounding rock pressure of $\mathrm{K} 6+570$ was $65.7 \mathrm{KPa}$, and the minimum pressure was $42.5 \mathrm{KPa}$. Comparison of other groups of monitoring data showed that the monitoring data of surrounding rock pressure had no obvious regularity.

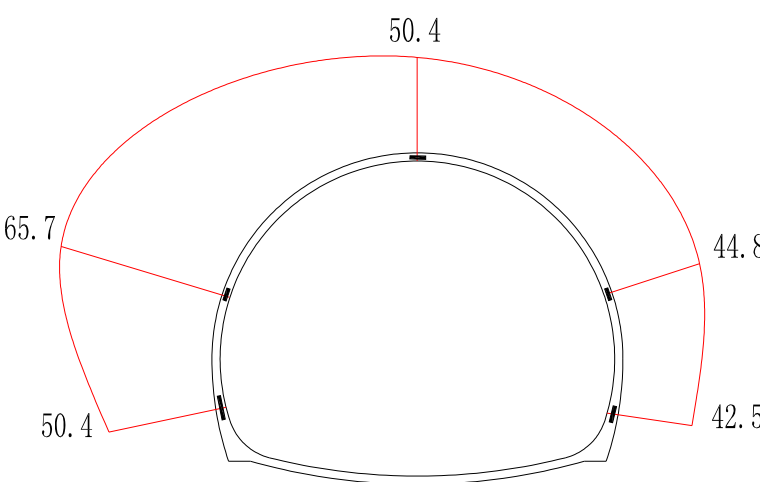

(b) Section K6+570 (bolt spacing 0.8m)

Figure 10. Envelope Diagram of Surrounding Rock-Primary Support Contact Pressure Distribution (unit: KPa))

\section{Conclusions}

Through the comparative analysis of numerical simulation calculation and field monitoring data under two working conditions of $0.8 \mathrm{~m}$ and $1.2 \mathrm{~m}$ system anchor bolt circumferential spacing in deep-buried section of class- $\mathrm{V}$ surrounding rock, the main conclusions that can be drawn are as follows:
1. Numerical simulation shows that: After the adjustment of the circumferential spacing of the system anchor bolts, the bolt axial force increases by about $15 \sim 20 \%$, but it is within the bearing capacity of the anchor bolts; the adjustment of the circumferential spacing of system anchor bolts has little influence on the change of tunnel displacement and the range of the plastic zone of the surrounding rock at the top of the tunnel. 
2. The monitoring data show that: After the adjustment of the circumferential spacing of system anchor bolts, the vault settlement value is slightly larger than that before adjustment, and the bolt axial force increases evidently by about $31.4 \%$. Before and after the adjustment of bolt spacing, the monitoring data of surrounding rock pressure has no obvious regularity.

3. In terms of surrounding rock integral deformation and bolt axial force, the numerical simulation and field monitoring data show a consistent trend, that is, the adjustment of the circumferential spacing of system anchor bolts has little influence on the settlement of surrounding rock, and the bolt axial force increases after the optimization of the spacing of system anchor bolts.

In summary, the adjustment of the circumferential spacing of system anchor bolts in the deep-buried section of class- $\mathrm{V}$ surrounding rock from $0.8 \mathrm{~m}$ to $1.2 \mathrm{~m}$ has little influence on the stability of the overall structure of the tunnel. After adjustment, it not only saves the construction schedule of the system anchor bolts, but also saves the project cost. It should be pointed out that, due to the reduction of system anchor bolts, the dynamic tracking of construction quality and monitoring measurement of feet-lock bolts should be strengthened, and the primary support should be closed into a ring as soon as possible to ensure construction safety.

\section{Acknowledgments}

This work is jointly supported by the National Key Research and Development Program of China 2018YFC0809605.

\section{References}

1. Shi Zhengbao, Li Xianmin, Chen Baoxiang. Experimental study on bolt effect of lijiazhai tunnel system in Guizhou Province[J]. Hydrogeology and engineering geology, 2020,47 (1)

2. Chongqing traffic research and Design Institute Co., Ltd. of China Merchants Bureau. Code for design of highway tunnel volume I civil engineering JTG 3370.1-2018[S].Beijing: People's transportation press. 2018

3. $\mathrm{Xu}$ Ligong, $\mathrm{Li}$ Hao, Chen Xianglin, et al. Numerical analysis of the influence of bolt parameters on the stability of surrounding rock [J]. Journal of geotechnical engineering, 2010, 32 (2): 249-252

4. Li Dejun, Yu Cheng Shuo, Xie Dongwu, et al. Optimization of initial support parameters of Shanling tunnel in large-span cities [J]. Modern tunnel technology, 2020,57 (S1): 387-393

5. Wang Zhiwei, song Mengyang, Jin Hui, et al. Analysis and Research on optimal bolt spacing of three lane tunnel with grade IV surrounding rock ( J ) . Railway construction technology, 2018 (12): 86-92
6. Yin Haibo, Yang Ziyou, Cheng Changqing. Simulation analysis of surrounding rock reinforcement effect of a soft rock roadway under different anchoring parameters ( $\mathrm{J}$ ) . Journal of Lanzhou Institute of technology, 2021,28 (1): 13-18

7. Meng Yafeng, Xiao Donghui, Kong Dekun, et al. Study on bolt effect of large section shallow buried sandy clay tunnel system [ J ] . Construction technology, 2019 (11): 98-113

8. Shen Zhijun, Zheng Yuchao, Gong Lun, et al. Key technologies for design and construction of mining method tunnel of Menghua heavy haul railway[J]. Chinese Journal of highways, 2020, 33 (12)

9. Chen Jianxun, Qiao Xiong, Wang Mengshu. Stress and action mechanism of rock bolt in loess tunnel[J]. Chinese Journal of Rock Mechanics and Engineering, 2011, 30 (8):1690-696 